\title{
Karl-Reinhart Trauner
}

\section{ZGODNJA TOLERANCA V AVSTRIJSKIH OBOROŽENIH SILAH}

V Tolerančnem patentu cesarja Jožefa II. (1741-1790) iz leta 1781 je v 17. odstavku med drugim določeno:

Pri vseh izvolitvah in podeljevanju služb je treba ne glede na razlike v religiji natančno upoštevati poštenost in kompetentnost, pa krščanski in moralni način življenja, tako kot se to dela vsakodnevno in brez odstopanja v naši vojski (Frank 1882, 39-40; prim. Tolerančni 2011, 299-300). ${ }^{1}$

Pri podeljevanju vodstvenih položajev naj torej konfesionalna pripadnost ne igra nobene vloge, vzor temu je prav vojaška služba. To je toliko bolj vredno pozornosti, saj so bili evangeličani pred tolerančnim patentom dvesto let zatirani in na veliko tudi preganjani (Schwarz 2012c; 2017) kljub že tedaj obstoječim izjemam na Ogrskem in predvsem na Sedmograškem.

\section{Ambivalentnost}

Po 3o-letni vojni in spreminjanju habsburškega cesarstva v moderno državo z moderno vojsko (Deák 2015; Trauner 2012) ter z znova povečano ogroženostjo s strani Osmanskega imperija v 17. in 18. stoletju

1 Obstajajo številne različne inačice besedila patenta že v nemščini. Pregled o tem nudi Barton 1981. Za prevod v slovenščino glej Tolerančni patent 1781, 2011. 
so konfesionalni konflikti zgubili svojo dinamiko. Malce zajedljivo, a ustrezno, bi bilo pripomniti, da so Habsburžane k popuščanju silile tudi finančne stiske. Vojaške enote iz habsburških dežel so se zato bojevale skupaj s četami iz cesarstva, ki so bile že od 16. stoletja dalje sestavljene konfesionalno paritetno. Kljub protireformaciji so tako v habsburško službo prišli tudi evangeličanski vojaki in včasih dosegli vodilne položaje. Evangeličansko cerkveno zgodovinopisje je na to dejstvo že zgodaj opozorilo. ${ }^{2}$

Dober primer za to je Friedrich Heinrich von Seckendorff (16731763). Ob novem izbruhu vojne s Turki je bil na željo princa Evgena (1663-1736) leta 1714 povabljen v cesarsko službo in hitro napredoval kot oficir in diplomat kljub svoji evangeličanski veroizpovedi. Njegov primer pa pokaže tudi meje te odprtosti. Princ Evgen ga je malo pred smrtjo, leta 1736, predlagal za svojega naslednika, »če se odpove svoji religiji« (Dauber 2007, 145). Dvorni vojni svet se z njegovim imenovanjem za vrhovnega poveljnika cesarske vojske ni strinjal - nenazadnje zaradi konfesionalne pripadnosti. Ko je bil Seckendorff na predstavitvi pri cesarju Karlu VI. (1685-1740), je ta od njega naravnost zahteval, da postane katoličan, kar pa je johanitski vitez Seckendorff odklonil, sklicujoč se na svojo zvestobo evangeličanskemu nauku.

Dober vpogled v razmere v vojski ponuja poročilo hannovrskega poslanika Johanna Basiliusa Küchelbeckerja (1697-1757) na dunajskem dvoru iz leta 1730:

Kar zadeva religijo, se tukaj ne razpravlja, ali je nek oficir ali vojak katoliški ali protestantski, če je sicer častivreden možak. Zato v cesarski vojski ne najdemo le mnogo oficirjev in vojakov, temveč tudi polkovnike in generale, ki niso rimskokatoliški, a so poznani po svoji sposobnosti. (Küchelbecker 1730, 276)

Vsekakor pa v vojski ni bila dovoljena evangeličanska duhovna oskrba [Seelsorge] (Tepperberg 1996, 132). Do kratkotrajnega koraka nazaj je prišlo pod vplivom vicekanclerja v avstrijski državni pisarni Johanna

2 Iz starejšega zgodovinopisja naj opozorim na: Trautenberger 1901, 205-8; Loesche 1911, 783; Stökl 1953, 245. Glej tudi Hanak [1971/1972] 1974, 31-34. 
Christopha von Bartensteina (1689-1767), ki je bil luteran, a je leta 1715 prestopil v katolištvo. Že leto dni po smrti princa Evgena so bili odslovljeni vsi evangeličanski poveljniki v avstrijski službi. Položaj se je spet spremenil po letu 1765, ko je Jožef II. postal sovladar in prevzel skrb za vodenje vojaških zadev (Hanak [1971/1972] 1974, 32, 35). Velik vpliv je imel tudi izgon jezuitov iz habsburškega cesarstva po letu 1773 (potem ko je papež Klemen XIV. julija 1773 ukinil jezuitski red³). Jezuiti so bili pogosto vladarjevi spovedniki in hkrati voditelji dušnopastirske službe v vojski (Hanak [1971/1972] 1974, 36).

Spoznanje, da so vojaške sposobnosti, značaj in osebne kreposti v oboroženih silah pomembnejše od konfesionalne pripadnosti, se je $\mathrm{v}$ njih vedno bolj uveljavljalo. ${ }^{4} \mathrm{~V}$ tem smislu je bila razumljena tudi naloga, »napravite mi iz njih sposobne oficirje in poštene može«, ki jo je dala Marija Terezija (1717-1780) ob ustanovitvi Terezijanske vojaške akademije v Dunajskem Novem mestu njenemu prvemu komandantu, feldmaršalu Leopoldu Josephu von Daunu (1705-1766). ${ }^{5}$ Tako se je v vojski že zgodaj oblikovala svojevrstna simbioza med strpnostjo do državne strpnosti in patriotizmom $z$ deloma kar otroškim čaščenjem vladarja; ta simbioza je bila tipična za protestantizem 19. stoletja. (Schwarz 2016/17)

\section{Služenje v vojaški enoti}

Tak razvoj je odločilno vplival tudi na življenje v vojaški enoti. V 18. stoletju ni bil več v ospredju konflikt $\mathrm{z}$ Osmanskim cesarstvom, ampak vprašanje, kako zagotoviti stabilnost habsburškega imperija po smrti Karla VI. leta 1740. Cesar ni imel moških potomcev in njegova hči se je morala bojevati za uveljavitev svoje dediščine. $V$ avstrijski nasledstveni vojni $1740-1748$ so si Wittelbachi lastili habsburške dežele, Friderik II. Pruski (1712-1786) pa je leta 1740 vkorakal v Šlezijo. Prva (1740-1742) in

3 Red je ponovno dopustil papež Pij VII. (1742-1823) leta 1814.

4 Za celotno področje glej med drugim Shek Brnardić 2010.

5 Za zgodnjo zgodovino akademije glej Leitner von Leitnertreu 1852, 190-239. 
druga (1744/45) šlezijska vojna sta bili za Prusijo uspešni. V dresdenskem miru 1745 je bilo potrjeno, da Šlezija razen majhnega dela pripada Prusiji, Friderik II. pa je priznal Terezijinega moža, Franca I. Štefana (1708-1765), za cesarja Svetega rimskega cesarstva.

Pridobitev Šlezije je imela za Prusijo tudi konfesionalne posledice. Katoliško prebivalstvo v Prusiji se je povečalo za osemkrat. Po drugi strani je imel spopad med Prusijo in Avstrijo tudi indirektne konfesionalne razsežnosti: Avstrija, trdnjava katolicizma, se je bojevala s protestantsko Prusijo; politična polariziranost med Avstrijo in Prusijo je bila tudi konfesionalna. Kljub vsemu pa se je avstrijska vojska dobro bojevala tako v nasledstveni vojni kot v obeh šlezijskih. ${ }^{6}$ Izkušnje so spodbudile reforme, med njimi tudi ustanovitev omenjene Terezijanske vojaške akademije leta 1751. Sredi 18. stoletja je konflikt zaradi Šlezije ponovno izbruhnil. Tretja šlezijska vojna je bila tokrat del daleč večjega vojnega spopada: $v$ sedemletni vojni (1756-1763) so se bojevale vse tedanje evropske velesile.? Za avstrijsko vojaško zgodovino je bila pomembna bitka pri Kolinu. V njej so 18. junija 1757 avstrijske čete prvič premagale Friderika II., ki je do takrat veljal za nepremagljivega na bojišču. Zmaga je bila povod za ustanovitev najvišjega staroavstrijskega vojaškega odlikovanja, »Vojaški red Marije Terezije« (Mader 2007b; Ortner 2019). Kljub vsem takratnim govoricam odlikovanje ni bilo podeljevano za dejanja v nasprotju $\mathrm{z}$ ukazi, temveč za uspešna vojaška dejanja, ki so bila storjena iz lastne iniciative in so bistveno vplivala na izid spopada, pa čeprav bi jih lahko časten oficir tudi brez graje opustil. Statut reda, člen 21 (Statuten 1811, 10), je določal:

Za odlikovanje so zaslužna [...] vsa tista dejanja, ki bi bila lahko brez odgovornosti opuščena, pa so bila kljub temu storjena: na primer, če oficir tvega napad brez posebnega ukaza in pri svojem delovanju pri tem ne izkazuje le predpisane drže, ampak tudi osebno srčnost [...].

6 O armadi v času Marije Terezije glej Duffy 1977; Hochedlinger 2003.

7 Sedemletna vojna je bila prva svetovna vojna $v$ novejši zgodovini. Težišče ni bilo $v$ Evropi, ampak v Severni Ameriki in Indiji. Spopad med Anglijo in Francijo se je bil za prevlado v svetu. 
Po zgoraj omenjenem poročilu so obstajali regimenti, v katerih je bila več kot polovica protestantov. Zaradi konfesionalnega ozadja šlezijskih vojn so bile pomembne tudi smernice glede konfesionalnosti. Državni kancler Wenzel Anton Kaunitz (1711-1794) se je v razpravi o ustanovitvi in pravilih reda zavzel za konfesionalno nevtralnost, saj je bilo v avstrijski vojaški službi mnogo protestantov: odlikovanje zato ne sme biti poimenovano po nekem svetniku [kot je bilo do tedaj pravilo] niti ne sme biti okrašeno z neko svetniško podobo (Mader 2007b, 440). V 4. členu statuta je bilo jasno določeno, da se odlikovanje podeli oficirjem »brez ozira na njihovo religijo, rang in druge okoliščine» (Statuten 1811, 4).

Versko nevtralna drža se je izrazila tudi v poimenovanju odlikovanja, ki je poudarilo zavezanost oficirja izključno in samo vladarju. Drža je dobila svoje mesto tudi v vzgoji oficirjev: za vrednotni svet oficirja ni bila več odločilna konfesionalnost, ampak državnopolitična miselnost. Pod poveljstvom direktorja generalmajorja Franza Josepha Kinskega (1739-1805) »je bilo težišče vzgoje v oblikovanju patriotskega mišljenja in zvestobe vojaka do cesarske hiše " (Steiger in Gansdorfer 2002, 12). ${ }^{8}$

De facto je bila v vojski vsaj tolerirana, če ne tudi sprejeta, zasebna religiozna praksa. Pomembno vlogo so pri tem na Dunaju imele evangeličanske kapele na veleposlaništvih, na Danskem in Švedskem za luterane, na Nizozemskem za reformirane. V Trstu je bila leta 1778 ustanovljena evangeličanska občina za vojake, mornarje in oficirje (Hanak [1971/1972] 1974, 43). Obisk veleposlaniških kapel in evangeličanske občine v Trstu je bil vojakom celo uradno dovoljen (Otto 1886, 122; Trautenberger 1901, 205-7) ${ }^{9}$.

Vpogled omogoča tudi poročilo Johanna Hieronymusa Chemnitza (1730-180o), ki je bil od leta 1757 do 1768 kraljevi danski pridigar na veleposlaništvu na Dunaju. Iz poročila za leto 1761 izvemo, da so se božje službe na veleposlaništvu udeležili številni oficirji in navadni vojaki:

V kraljevsko dansko veleposlaniško versko občino prihajajo naslednje osebe [...] mnogi cesarski oficirji in vojaki [...] Njihovo število se je v

8 Glej tudi Shek Brnardić 2017.

9 O ustanovitvi občine v Trstu glej ustrezna poglavja pri Patzeltu 1999. 
zadnjem času zelo povečalo, potem ko so bili mnogi evangeličanski Prusi sprejeti v tukajšnje službe (Chemnitz 1761, 10).

Chemnitz je tudi prepričljivo opisal konkretno božjo službo s sveto večerjo za pripadnike vojske (1761, 23-24).

$\mathrm{Tu}$ je omenjeno še drugo dejstvo, ki je bilo v ozadju nadkonfesionalnih opredelitev Vojaškega reda Marije Terezije. Med šlezijskimi vojnami so bili zajeti številni pruski oficirji in vojaki. Avstrijska vojska je po eni strani potrebovala popolnitev moštva zaradi vojnih izgub, po drugi strani pa je bilo pri reformiranju avstrijske vojske nadvse dobrodošlo strokovno znanje ene najuspešnejših armad tistega časa. Prizadevali so si torej, da bi v avstrijsko službo sprejeli pruske oficirje in vojake, ne glede na njihovo veroizpoved.

Konfesionalni konflikti naj ne bi imeli več mesta v oboroženih silah avstrijske države, čeprav je bila ta sicer še kako povezana s Katoliško cerkvijo. Ta drža je bila tudi v ozadju drugih glavnih službenih predpisov 18 stoletja. Pravilnik za celotno cesarsko in kraljevo pehoto iz leta 1769, ki ga je oskrbel feldmaršal Franz Moritz von Lacy (1725-1801) (Kotasek 1956, 96-106), zelo jasno povzema stališče o konfesionalnih zadevah:

O religiji naj se nikdar ne govori, zato pa toliko bolj živi v skladu z njo; z najstrožjo in neizogibno kaznijo je prepovedano vse, kar bi lahko bilo povod za sovražnost med pripadniki različnih ver. (Kotasek 1956, 60)

Vendar je bilo v oboroženih silah odločno prepovedano vse, kar bi lahko dajalo vtis javnega prakticiranja vere. Tako je bil leta 1774 poklican na odgovornost pred dvorni vojni svet reformirani pastor iz Sedmograške, pristojni vojaški poveljnik pa okaran, ker je pastor obiskal nekega vojaka v kasarni. Evangeličanska duhovna oskrba v kasarni bi pomenila, da je evangeličansko bogoslužje vsaj delno prestopilo iz zasebnosti v javno sfero (Tepperberg 1996, 133).

Številni dogodki v sferi verske politike Marije Terezije kažejo, da je bila zgodnja religiozna toleranca omejena na oborožene sile in ni veljala za državo kot celoto. Še leta 1776 so bile iz konfesionalnih razlogov na zahtevo Marije Terezije (in proti volji njenega sina in sovladar- 
ja Jožefa II.) izvedene nasilne preselitve [»transmigracije»] iz Stadla ob Muri (Knall 2002, 132-257).

\section{Tolerančni patent}

Marija Terezija je umrla 29. novembra 1780 in že po nekaj dneh je njen sin in naslednik začel uvajati novo versko zakonodajo (Kuzmič 2011, 307-8). Že 31. decembra 178 o je odpravil verske komisije; sledili so drugi predpisi. Z dvornim dekretom 30 . januarja 1781 je določil, da »ne sme biti v nobenem predpisu razlikovanja med katoliki in protestanti« (Handbuch 1785, 421).

Že pred izdajo Tolerančnega patenta oktobra $1781^{10}$ so bile po hitrem postopku zaporedoma odpravljene vse prepovedi za protestante (Desput 1981, 111). V državnem svetu in dvorni pisarni so vneto in kontraverzno razpravljali o političnih smernicah. Na cesarski ukaz je bilo dvornemu svetu predloženo v presojo anonimno besedilo z naslovom Opažanja o religijskem razlikovanju (Betrachtungen über Religionsdifferenzen) (Frank 1882, 21-23), v katerem se govori tudi o razmerah v vojski. Vojska je bila predstavljena kot »zanesljiv in že dolgotrajen primer«, ki spodbuja, da se mu »zaupa in sledi«. V vojski se namreč

razlika v religiji v nobenem primeru ni obravnavala, in to od najnižje stopnje do feldmaršala in vojnega predsednika [...]. Vsak je bil obravnavan po svojem obnašanju, svojih sposobnostih, trudu in službeni vnemi, vsak je lahko veroval, kar je bilo po njegovem prepričanju najboljše. Vsak je lahko prakticiral svojo vero, če le ni zato zanemarjal svojih službenih obveznosti; ni bilo dovoljeno govoriti niti za niti proti niti komurkoli koga drugega zapeljevati ali spravljati v zmoto. (Frank 1882, 21)

V nadaljnjih predlogih anonimnega avtorja najdemo tudi formulacije, ki so bile potem skoraj dobesedno vključene v Tolerančni patent. Če bi tolerirali konfesionalne razlike in upoštevali konfesionalne posebnosti,

10 Patent je bil dejansko izgotovljen 20. oktobra 1781, a antidatiran na 13. oktober. 
bi najhitreje lahko uživali prave sadove. Lahko upamo, da bodo kmalu odpravljena vsa nasprotja in spori in bo država obogatena s koristnimi in spretnimi državljani, delno iz tujine in delno iz lastnih dežel, če se le bo pri vseh izvolitvah in službenih imenovanjih - tako kot brez vsakih zadržkov že vsakodnevno v vojski - gledalo samo na spretnost in poštenost pretendentov in posebej upoštevalo njihovo krščansko in moralno življenje. (Frank 1882, 22f)

Tu lahko gotovo mislimo tudi na številne evangeličanske oficirje iz nemških kneževin v avstrijski vojaški službi.

Vsekakor se je s tem našla argumentacija, ki jo kasneje najdemo v Tolerančnem patentu in ki je bila uporabljena v prvem kratkem sporočilu za javnost (Kundmachung):

[...] tako, kot se to plodno in brez zadržkov dogaja v vojski, da se ne gleda na razlike v religiji, ampak na poštenost in sposobnost pristojnih, pa na njihov krščanski in moralni način življenja (Frank 1882, 33).

Sporočilo za javnost je sicer napisal Tobias von Gehler (1720-1786), deklarirani zagovornik tolerance. Državni svetnik in vicekancler dvorne pisarne je bil blizu razsvetljenstva; po izvoru je bil evangeličan, a je leta $1783 \mathrm{iz}$ kariernih razlogov prestopil v katolicizem.

Cesar je patent podpisal 20. oktobra 1781; za tem je bil v različnih verzijah objavljen v posameznih habsburških deželah. Čeprav je izšel v različnih jezikih, doslej ne poznamo slovenske izdaje (Vinkler 2011, 302). ${ }^{11}$ Imel pa je seveda velik pomen tudi za slovensko prebivalstvo v monarhiji, saj je temeljito spremenil državno religijsko politiko. ${ }^{12}$

Ob preobratu $\mathrm{v}$ religijski politiki habsburškega cesarstva $\mathrm{s}$ Tolerančnim patentom pa ne smemo prezreti, da je bila jožefinska toleranca še zelo daleč od verske enakopravnosti. To lahko vidimo ob prepovedi javnega prakticiranja vere »akatolikov«. V preambuli patenta

11 Sklicuje se na Sergeja Vilfana, Pravna zgodovina Slovencev (Ljubljana: Slovenska matica, 1996), 382 .

12 Glej Kuzmič 2011, 308, ki se posebej ukvarja s Prekmurjem; tudi Schwarz 2012b (nemška različica 2012a). 
piše: »Privilegij [Vorzug] javnega prakticiranja vere torej ostane le katoliški religiji [...]«(Frank 1882, 37).

Evangeličanom in pravoslavnim je bilo dovoljeno le zasebno prakticiranje religije. ${ }^{13}$ Tolerance v Tolerančnem patentu zato nikakor ne smemo izenačevati z enakopravnostjo. To je vidno že pri vodenju matrik. Celo pri njih je še leta 1848 veljalo: „Če mora nekatoliški dušni pastir posredovati potrdila o krstu, poroki ali smrti, jih lahko veljavno preda uradnikom le preko katoliškega župnika, ki jim doda svoj Vidit.» (Streffleur 1848, 333).

Privatreligionsexercitium [zasebno prakticiranje religije] je bil »ključni upravno pravni pojem " (Schwarz) ${ }^{14}$, ki je dal tudi na zunaj na znanje, da so "akatoliške « Cerkve (kot se je takrat običajno reklo) le tolerirane in da je za Jožefa II. Katoliška cerkev še naprej "prava in edino odrešujoča religija«, kot je sam poudaril ${ }^{15}$ (Desput 1981, 121; Vinkler 2011, 304). Tolerančni patent je bil akt sicer razsvetljenega, a absolutistično vladajočega monarha v religijskih zadevah (Vinkler 2011, 305).

\section{Motivi za zgodnjo toleranco}

Patent takoj v začetku navede oba motiva, ki sta privedla do njegove izdaje: 1. »škodljivost prisile v zadevah vesti« in 2. »veliko korist za religijo in državo, ki izhaja iz prave krščanske tolerance (Frank 1882, 37).

Oba razloga ustrezata razsvetljenskemu svetovnemu nazoru, prvi bolj na filozofskem, drugi na državnopolitičnem utilitarnem področju. Nedvomno se za "veliko koristjo ... za državo" skrivajo tudi ekonomski razlogi (Vinkler 2011, 305). Jožef II. je tu v veliki meri sledil idejam

13 Izjeme so bile le občine v Šleziji in Galiciji, ki jim je starejši pravni red cesarstva dopuščal javno prakticiranje vere. Tako obstoječe izjeme omeni tudi Tolerančni patent $\mathrm{v}$ svoji preambuli.

14 Tako Karl W. Schwarz v svojem predavanju »Učinki Tolerančnega patenta v evangeličanskem prostoru « na Klemens-Maria-Hofbauer simpoziju na Dunaju (Lainz) 22./23. junija 2001. O zasebnem prakticiranju vere glej mdr. Schwarz 1988.

15 Citat najdemo tudi v dvorni resoluciji (Hofentschließung) z dne 26. 4. 1782 (Handbuch 1785, 458). 
svojega velikega vzornika in političnega nasprotnika, pruskega kralja Friderika II. ${ }^{16}$

Sicer pa se je od Friderika tudi razločno distanciral. Medtem, ko je Jožef II. še vedno vztrajal pri predstavi katoliške državnosti, najdemo pri Frideriku II. že začetno obliko moderne verske nevtralnosti. V svojem tako imenovanem Političnem testamentu iz leta 1752 je nedvoumno pripomnil:

Za politiko je povsem brez pomena, ali je vladar religiozen ali ne. [...] Mora se le toliko upoštevati množice, da se ne prizadene njihovih religioznih čustev, ne glede na to, katere vere so (Friedrich der Große 1922, 25).

V Političnem testamentu leta 1768 Friderik celo izjavi, »da države nič ne briga, kateri metafizični nazor tiči v človekovih možganih, dovolj je, da se obnaša kot dober državljan in patriot « $(1922,194)$. Tako omejevanje na zahtevano državljansko držo najdemo sredi 18. stoletja v avstrijski vojski in leta $1781 \mathrm{v}$ Tolerančnem patentu, toda le v vsebinski, pozitivni obliki.

$\mathrm{V}$ vojski do zgodnje tolerance ni prišlo zaradi razsvetljenskih idejnih razlogov. Odločilno je bilo vprašanje vojaške udarne moči. Temu so bila podrejena vsa druga vprašanja, tudi konfesionalna. Religijske razlike so bile tolerirane $\mathrm{v}$ senci te prioritete, bolje rečeno, zaradi nje se je gledalo preko njih.

Še leta 1780 - eno leto pred Tolerančnim patentom - je bil kaznovan desetar, ki mu je bilo luteranstvo očitno blizu, ker ni bil dovolj prizadeven pri aretaciji nekega luteranskega duhovnika. Premeščen je bil na Ogrsko, dvorni vojni svet pa je poskrbel za katoliško vzgojo njegovih petih otrok (Tepperberg 1996, 133).

Poleg omenjene prioritete se je pazilo tudi na to, da bi se izognili konfliktom, kot priča Ureditev za celotno cesarsko kraljevo pehoto (Reglement für die sämmentlich Kaiserlich-Königliche Infanterie) iz leta 1769. Z dvornim dekretom 28 . avgusta 1781 se je prepovedalo vsako prisilo v religijskih zadevah, »dokler se zmotno verujoči prebivalci dežel obnašajo mirno in miroljubno « (Handbuch 1785, 421). ${ }^{17}$

16 Za zgodovino misli o toleranci glej Schwarz, 1985.

17 Dvorni dekret $z$ dne 28. 8. 1781 (Handbuch 1785, 421-22). 
Ta motiv vedno znova najdemo $\mathrm{v}$ določilih o implementaciji Tolerančnega patenta. Zato je v njih prepovedana agresivna kontraverzna teologija ali misijonarjenje katoliških župnikov:

$[\mathrm{P}] \mathrm{o}$ pravem smislu krščanske tolerance se je treba ljubeznivo in $\mathrm{z}$ vso prijaznostjo obnašati tudi do tistih, ki se $\mathrm{v}$ veri motijo (Handbuch 1785 , $435)^{18}$

Prav tako pa je prepovedano tudi, da bi evangeličanski pastorji $\mathrm{k}$ svojim pobožnostim pripuščali še druge osebe razen tistih, ki so se po uvedbi Tolerančnega patenta izjasnile za protestantizem (Handbuch 1785, 429). ${ }^{19} \mathrm{Za}$ Jožefa bi bilo slednje zloraba tolerance in bi vodilo do nemirov. Tolerirane protestante svari,

naj podeljene svobode vesti ne zlorabljajo za nesprejemljiva dejanja in naj ne izzivajo namerno katoliških podanikov in naj ne dajejo s tem sami povoda za neprijetne posledice (Handbuch 1785,466$){ }^{20}$

Uradnikom »je ukazano, da [...] vzdržujejo molk med ljudmi glede religijskih razlik in $\mathrm{s}$ tem prispevajo $\mathrm{k}$ skrbi za vsestransko vzdrževanje miru " (Handbuch 1785, 435). ${ }^{21}$ Uredba spominja na Ureditev za vojsko iz leta 1769. Zaukazana toleranca je nenazadnje služila vzdrževanju družbene stabilnosti in uspešnemu nadaljnjemu razvoju, kot se je to pokazalo v vojski.

$\mathrm{Z}$ druge strani, s strani religije, pa Jožef - povsem $\mathrm{v}$ razsvetljenskem smislu - pričakuje skrb za družbeno in državno moralo: „V državi ni mogoče trpeti nobenega verskega nauka [...], ki nima kot temeljnega načela moralnost svojih vernikov [...] (Handbuch 1785,452$){ }^{22}$ Od pridigarjev Jožef ne pričakuje »toliko razsvetljevanja razuma, kot skrb za vsaditev kreposti in izboljšanje srca» (Handbuch 1785, 52). ${ }^{23}$ Čeprav so tu

18 Dvorni reskript $z$ dne 14. in 24. 10. 1781 ter 14. 1.1782 (Handbuch 1785, 434-35).

19 Dvorni dekret $z$ dne 17. 11. 1782.

20 Dvorni dekret $\mathrm{z}$ dne 9. 9.1783.

21 Dvorni dekret $\mathrm{z}$ dne 19. 3. 1782.

22 Dvorni dekret $\mathrm{z}$ dne 25. in 31. 1. 1782.

23 Dvorni dekret $\mathrm{z}$ dne 04. 2. 1783 (Handbuch 1785, 51-52). 
mišljeni katoliški pridigarji, pa ta pričakovanja nedvomno veljajo tudi za evangeličanske.

Poleg teh motivov, ki se nanašajo na religije v družbenem življenju, je bil verjetno navzoč še nek drug, doslej komajda obravnavani, motiv. Od srede 18. stoletja dalje je bilo avstrijsko prebivalstvo zajeto tudi v statistike. Prvo ljudsko štetje v Avstriji je bilo izvedeno pod Marijo Terezijo leta 1754 po upravni reformi. ${ }^{24} \mathrm{~V}$ tej zvezi pade v oči pripomba, ki se nanaša na uveljavljanje Tolerančnega patenta: registracija evangeličanov po določilih patenta je bila potrebna »le zato [...], da bi zvedeli za njihovo število« (Handbuch 1785, 453). ${ }^{25}$ Lahko torej domnevamo, da je šlo Jožefu tudi za to, da ima čim stvarnejši statistični pregled o prebivalstvu svojih dežel. K tej stvarni podobi je spadalo tudi njegovo kategoriziranje po verski pripadnosti, kasneje pa tudi po narodni (gl. Stergar in Scheer 2018). Raznolikosti prebivalstva in obstoja "akatoliških « religijskih skupin v drugi polovici 18. stoletja ni bilo več mogoče prezreti, kljub drugačni pravni ureditvi.

Tolerančni patent tako ni bil le izraz strpnosti do evangeličanov in pravoslavnih (ter malo kasneje v Spodnji Avstriji in na Dunaju tudi do Judov), temveč tudi realističnega upoštevanja aktualnega verskega položaja habsburškega cesarstva.

\section{Implementacija patenta}

Zaradi patenta je bilo dovoljenje za privatno prakticiranje vere razširjeno tudi na "akatoliške« vojake, kolikor taka praksa v cesarskokraljevskih regimentih ni obstajala že prej. Še vedno pa se je izhajalo iz prvenstva katoliške veroizpovedi; evangeličanska - tako luteranska kot reformirana - in pravoslavna sta bili pač le tolerirani. ${ }^{26}$ Čeprav je v vojski že obstajala de facto toleranca, je vsakdanje življenje pričalo,

24 Glede razvoja popisov prebivalstva gl. mdr. Durdik 1973.

25 Dvorni dekret z dne 15. 4. 1782.

26 O pravnem položaju »akatoličanov« $\mathrm{v}$ času po Tolerančnem patentu v povzetku Schima 2011/12 
da je izenačenost še daleč. Že Opazovanja o religijskih razlikah so ugotavljala: »Spreobrnitve so kljub temu zelo pogoste in to ne zaradi hlinjenja (Frank 1882, 21).

Zaradi močnega odpora niso bile ustanovljene vojaške molilnice, ki jih je Jožef načrtoval (Loesche 1911, 787; Hanak [1971/1972] 1974, 57; Reichl-Ham 2005, 12). Tudi po letu 1781 so smeli evangeličanski duhovniki v kasarne ali vojaške bolnišnice priti le na izrecno željo obolelega vojaka (Tepperberg 1996, 133). Organizirane duhovne oskrbe vojakov ni bilo, saj javno prakticiranje vere ni bilo dovoljeno; omogočena je bila le omejena oskrba za posamezne vojake (Schima 2011/12, 234).

Cesar je očitno dvomil, da se bo položaj v doglednem času kaj spremenil. Samo tako si lahko razložimo opozorilo, ki ga je Jožef II. hkrati $\mathrm{z}$ izdajo patenta naslovil na dvorni vojni svet:

Sicer pa bo dvorni vojni svet $\mathrm{z}$ ustreznimi ukazi uradnikom in v skladu z vsemi v vojski obstoječimi ukazi odpravil religiozno prisilo glede nesprejemanja protestantskih kirurgov in komandantov, nepripuščanja evangeličanskih duhovnikov $\mathrm{k}$ protestantom $\mathrm{v}$ bolnicah in ob eksekucijah in končno glede dovoljenja, da protestantski vojaki v skladu $\mathrm{z}$ možnostmi obiskujejo protestantske cerkve in tam sprejmejo obhajilo. (Frank 1882,35)

Doslednega uresničevanja patenta ni ovirala le počasnost službenih postopkov, ampak tudi omejene realne možnosti in težave. Vojaški oddelki so bili večkrat nameščeni v krajih, kjer ni bilo evangeličanskih molilnic ali pa obisk božje službe zaradi velikih razdalj ni bil mogoč. Oddelki so večkrat letno menjali svoje nastanitve, tako da je bila kontinuirana duhovna oskrba s strani lokalnih pastorjev komaj mogoča. Četudi je bila redna udeležba pri božji službi obvezna tako za katoliške kot "akatoliške« vojake, nimamo kaj dosti dokazov, da so protestantski vojaki dejansko lahko obiskovali svoje obrede. V praksi je to pomenilo, da so bili mnogokrat prisiljeni obiskovati katoliške maše (Hanak [1971/1972] 1974, 38; Tepperberg 1996, 133). Podobno velja za duhovno oskrbo bolnih vojakov, ki so bili pogosto zaupani katoliškim vojaškim duhovnikom. Še v spisu iz leta 1842 lahko beremo: 
Ker so v vojaških vrstah tudi verniki akatoliških religij in judaizma ter so kot bolniki ali ranjenci zdravljeni v bolnišnicah, naj vojaški duhovniki ljubeznivo poskrbijo tudi zanje v skladu s smernicami Tolerančnega patenta (Leonhard 1842,164).

V praksi je to pripeljalo do » stanja streznitve« (Hanak [1971/1972] 1974, 39) spričo dosežene strpnosti na eni strani in dejstva, da se je zaradi Tolerančnega patenta število evangeličanov vojski še povečalo, na drugi.

Počasi so le nastale evangeličanske gmajne, tudi znotraj vojske, najprej v Pragi, Brnu in Olomoucu. Pozornost zasluži razvoj v Pragi, ki se je začel leta 1782 (Trautenberger 1901, 205; Hanak [1971/1972] 1974, 40). Gonilna sila je bil Dagobert Sigmund von Wurmser (1724-1797), ki je značilen primer za evangeličanske častnike, ki so vstopili v avstrijske oborožene sile. ${ }^{27} \mathrm{Zdi}$ se, da je imela pri tem neko vlogo tudi njegova pripadnost prostozidarstvu (Mader 2007a, 38).

Wurmser je začel svojo vojaško pot leta $1741 \mathrm{v}$ francoski službi in se udeležil sedemletne vojne, kmalu zatem pa je vstopil v avstrijsko službo in bil leta 1763 imenovan za generalmajorja. Po uspešnem poveljevanju v bavarski nasledstveni vojni (1778/79) je postal poveljujoči general v Galiciji, leta 1787 general konjenice in leta 1795 končno cesarski feldmaršal.

Vojaška občina v Pragi (prav tako kot cerkvena občina v Brnu) je bila med redkimi tolerančnimi občinami v čeških deželah, ki so spadale med tako imenovane patronatske občine. To pomeni, da v prvi vrsti ni bila vzdrževana z obveznimi prispevki vernikov, ampak s sredstvi cerkvenega patrona v okviru zakonodaje o patronatih (Melmuková 1999, 144-46). Wurmser je kot patron občino v veliki meri vzdrževal iz lastnega premoženja, poleg tega pa je uvedel še letni prispevek. Bil je v stalnem stiku z mlado evangeličansko občino v Brnu. V državnem svetu je spodbujal - brez pravega učinka sicer -, da bi za protestantske vojake avstrijske

27 Wurmser je bil krščen $\mathrm{v}$ reformirani cerkvi v Strasbourgu. Morda je iz kariernih razlogov v času službovanja prestopil v katolištvo. Podpiranje evangeličanske vojaške občine v Pragi vsekakor dokazuje njegovo vseživljenjsko povezanost s protestantsko veroizpovedjo. 
vojske uvedli Seilerjevo liturgijo, ki je bila takrat cenjena v protestantskih okoljih (gl. »Wurmser« 1890, 4) ${ }^{28}$ Zbirališče vojaške občine je bilo njegovo stanovanje v Palais Morzini; tudi božje službe protestantskih veleposlaništev so bile v stanovanjih samih veleposlanikov. Nameščen je bil celo poseben cesarsko-kraljevi vojaški pridigar, Christian Georg Samuel Schmidt iz Erlangna, ki je nastopil službo že leta 1782 in skrbel tudi za občino v vojaškem taboru v Hloubetinu, ki je danes del Prage (Reichl-Ham 2005, 12). Pomembno je, da je bila vojaška občina v Pragi izhodišče za oblikovanje drugih evangeličanskih občin. Jeseni 1782 je nastala prva češka luteranska občina, nemška pa je leta 1789 sploh izšla neposredno iz vojaške občine (Frank 1882, 91).

V Brnu je za evangeličanske vojake skrbela tudi nastajajoča civilna evangeličanska cerkvena občina. Pastor je bil Viktor Heinrich Riecke (1759-1830), ki je prišel iz Tübingena. Znano je, da je pred patentom vodil božje službe na danskem in švedskem veleposlaništvu na Dunaju (Bolom-Kotari 2016, 94). Njegovo delo je bilo uspešno, saj so mnogi oficirji z njim vzdrževali pisemske stike tudi potem, ko so zapustili garnizijo v Brnu (Hanak [1971/1972] 1974, 41).

Kot v Pragi je tudi evangeličanska vojaška občina v Olomoucu nastala na pobudo posameznika, feldmaršalskega poročnika Blasiusa Kolombana von Benderja (1713-1798). Von Bender je služil že pod princem Evgenom; leta 1775 je postal komandant garnizije v Olomoucu. Kot sicer katoliški oficir je že leta 1782 dopustil evangeličanske božje službe na spodbudo svoje evangeličanske soproge; v svojem tretjem zakonu je bil namreč poročen z Luiso (1731-1813), hčerko nemškega palatinskega (Kurpfalz) feldmaršalskega poročnika Wilhelma Moritza von Ysenburg-Philippseich. Ko je število evangeličanskih vojakov v garnizonu do leta 1785 naraslo na 340, je omogočil, da je prišel v Olomouc iz Brna pastor Riecke opravljat božje službe in duhovno oskrbo (ReichlHam 2005, 13).

28 Georg Friedrich Seiler (1733-1807) je bil profesor za teologijo v Erlangnu. Leta 1782 je objavil svoje prvo veliko delo o liturgiji Versuch einer christlich evangelischer Theologie. 


\section{Sklepna beseda}

Vojska ni bila le področje, na katerem so se lahko že zgodaj in potem v 19. stoletju emancipirale manjšine, kot so bili evangeličani ali Judje; ${ }^{29}$ bila je celo model za obravnavanje manjšin sploh. Že pred uradno tolerančno zakonodajo je bila v njej urejena toleranca ne le de facto, temveč od srede 18. stoletja dalje celo de iure. Motiv za to zgodnjo toleranco ni bila toliko ideja tolerance sama po sebi, ampak pragmatična drža, osredotočena na vojaško učinkovitost in skrb, da bi preprečevali konflikte znotraj oboroženih sil.

Nota bene: tudi določbe Protestantskega patenta iz leta $1861^{30}$ so bile v vojski uporabljene, še preden je ta stopil v veljavo, in sicer z zgraditvijo prve evangeličanske garnizonske cerkve na Dunaju (gl. Trauner 2005). Ob koncu monarhije je lahko katoliško-konservativni general Edmund Glaise-Horstenau (1882-1946) pripomnil (1980-88, 1:293), da »je bila verska strpnost [...] posebna značilnost cesarske armade « ${ }^{31}$. Pravilnik službe za vojsko (Dienst-Reglement $[1873]$ 1888, \$ 2, 13) je določal, da »ne sme vojak nikdar prizadeti spoštovanja, ki gre vsakemu religioznemu prepričanju«.

Vendar pa bi bilo evforično obravnavanje Tolerančnega patenta zgrešeno - pri njem je šlo za strpnost, ne za enako obravnavo. »[C]esarska politika [...] evangeličanom ni bila naklonjena« še dolga desetletja. Za časa cesarja Franza II. (1768-1835) so bili vidiki neenakega (neparitetnega) obravnavanja očitni (Schima 2011/12, 241, 256). „Seveda so bile v patentu še nekatere omejitve, vendar pa so se zadeve nasploh začele obračati na bolje« (Kuzmič 2011, 309). Vsekakor se je v veliki meri uveljavilo temeljno načelo, ki je bilo v vojski prakticirano že v 18. stoletju: da naj

29 O možnostih za judovske vojake gl. Silber 2005; gl. tudi ustrezna poglavja pri Schmidl 2014.

30 »Cesarski patent 8 . aprila 1861, s katerim so urejene zadeve evangeličanskih Cerkva augsburške in helvetske veroizpovedi, posebej njihova državnopravna razmerja [...] « (Reichsgesetzblatt 1861, 337-43).

$31 \mathrm{~V}$ sistematični navezi gl. tudi Reiss 2016, 83-89. 
se ne upošteva toliko religijske pripadnosti, ampak krščanski in moralni način življenja.

\section{VIRI IN LITERATURA}

Barton, Peter F. 1981. „'Das' Toleranzpatent von 1781: Edition der wichtigsten Fassungen." V Im Zeichen der Toleranz: Aufsätze zur Toleranzgesetzgebung des 18. Jahrhunderts in den Reichen Joseph II., ihren Voraussetzungen und ihren Folgen; Eine Festschrift (Studien und Texte zur Kirchengeschichte und Geschichte 2/8), ur. Peter F. Barton, 152-202. Dunaj: Institut für Protestantische Kirchengeschichte.

Bolom-Kotari, Sixtus. 2016. "Religiöse Toleranz und wirtschaftlicher Aufschwung: Die Brünner Evangelischen und der Wandel der Gesellschaft 1781-1815."Bohemia 56 (1): 88-121.

Chemnitz, Johann Hieronymus. 1761. Vollständige Nachrichten von dem Zustande der Evangelischen und insonderheitvon ihrem Gottesdienste bey der KöniglichDänischen Gesandschafts Capelle in der Kayserlichen Haupt und Residenzstadt Wien. Brez podatkov. http://digital.bib-bvb.de/view/bvbmets/viewer.o.6.4.jsp?folder_id=o\&d vs $=1577267191211 \sim 253 \&$ pid $=11012832 \&$ locale $=$ en\&usePid $1=$ true\&usePid $2=$ true

Dauber, Robert L. 2007. Johanniter-Malteser-Ritter unter kaiserlichen Fahnen 15231918. Gnas: Weishaupt.

Deák, John. 2015. Forging a Multinational State: State Making in Imperial Austria from the Enlightenment to the First World War (Stanford Studies on Central and Eastern Europe). Stanford: Stanford University Press.

Desput, Joseph. 1981. »Toleranz im Zeichen der Aufklärung: Zur Durchführung des Toleranzpatentes in der Steiermark." Mitteilungen des Steiermärkischen Landesarchivs 31: 105-21.

Dienst-Reglement für das kaiserlich-königliche Heer 1. (1873) 1888. Dunaj: Hof- und Staatsdruckerei.

Duffy, Christopher. 1977. The Army of Maria Theresia: The Armed Forces of Imperial Austria 1740-1780. Vancouver in London: David \& Charles.

Durdik, Christel. 1973. »Bevölkerungs- und Sozialstatistik in Österreich im 18. und 19. Jahrhundert." V Beiträge zur Bevölkerungs- und Sozialgeschichte Österreichs, ur. Heimold Helczmanovszki, 225-66. Dunaj: Verlag für Geschichte und Politik.

Frank, Gustav. 1882. Das Toleranz-Patent Kaiser Joseph II: Urkundliche Geschichte seiner Entstehung und seiner Folgen; Säcular-Festschrift des k.k. evangelischen Oberkirchenrathes A.C. und H.C. in Wien. Dunaj: Braumüller.

Friedrich der Große. 1922. Die Politischen Testamente (Klassiker der Politik 5). Prev. Friedrich von Oppeln-Bronikowski. Berlin: Hobbing. 
Glaise von Horstenau, Edmund. 1980-88. Ein General im Zwielicht. Die Erinnerungen Edmund Glaises von Horstenau 1-3 (Veröffentlichungen der Kommission für Neuere Geschichte Österreichs, 67, 70 u. 76). Ur. Peter Broucek. Dunaj, Köln in Gradec: Böhlau.

Hanak, Julius. (1971/1972) 1974. Die Evangelische Militärseelsorge im Alten Österreich unter besonderer Berücksichtigung ihrer Eingliederung in den kirchlichen Verband (Separat iz: Jahrbuch für die Geschichte des Protestantismus in Österreich 87/88). Dunaj: Evang. Presseverband.

Handbuch aller unter der Regierung des Kaisers Joseph des II. für die K.K. Erbländer ergangenen Verordnungen und Gesetze in einer Sistematischen Verbindung 2: enthält die Verordnungen und Gesetze vom Jahre 1780 bis 1784. 1785. Dunaj: Moesle.

Hochedlinger, Michael. 2003. Austria's Wars of Emergence: War, State and Society in the Habsburg Monarchy 1683-1797 (Modern Wars in Perspective). London, New York, Pariz, Amsterdam, München, Mailand/Milano, Toronto, Sydney, Tokio, Singapur, Hong Kong, Kapstadt, New Delhi in Madrid: Longman.

Knall, Dieter. 2002. Aus der Heimat gedrängt: Letzte Zwangsumsiedlungen steirischer Protestanten nach Siebenbürgen unter Maria Theresia (Forschungen zur geschichtlichen Landeskunde der Steiermark 45). Gradec: Historischen Landeskomm. für Steiermark.

Kotasek, Edith. 1956. Feldmarschall Graf Lacy: Ein Leben für Österreichs Heer. Horn: Berger.

Kuzmič, Franc. 2011. »Tolerančni Patent in Slovenci med Rabo in Muro.« Stati inu obstati 7 (13-14): 307-9.

Küchelbecker, Johann Basilius. 1730. Allerneueste Nachricht vom Römisch-Käyserl. Hof. Nebst einer ausführlichen Beschreibung der Kayserlichen Residentz-Stadt Wien und der umliegenden Örter [...]. Hannover: Förster.

Leitner von Leitnertreu, Theodor Ignatz. 1852. Ausführliche Geschichte der Wiener-Neustädter Militär-Akademie 1. Hermannstadt/Sibiu: Steinhäußer.

Leonhard, Johann Michael. 1842. Verfassung der Militär-Seelsorge in den k.k. österreichischen Staaten [...]. Dunaj: Lechner.

Loesche, Georg. 1911. Von der Duldung zur Gleichberechtigung: Archivalische Beiträge zur Geschichte des Protestantismus in Österreich 1781-1861 ([hkrati:] Jahrbuch für die Geschichte des Protestantismus in Österreich 32/33). Dunaj in Leipzig: Manz u. Klinkhardt..

Mader, Hubert Michael. 2007a. »Das Offizierskorps und die Freimaurerei des 18. Jahrhunderts." Österreichische Militärische Zeitschrift 55 (1): 31-42.

---. 2007b. „Vergangene soldatische Bravur: Der Militär Maria-Theresienorden.» Österreichische Militärische Zeitschrift 55 (4): 436-43.

Melmuková, Eva. 1999. Patent zvaný toleranční. Praga: Mladá Fronta. 
Ortner, M. Christian. 2019. „Der Militär-Maria-Theresien-Ordner.» Österreichische Militärische Zeitschrift 67 (5): 593-600.

Otto, Karl von. 1886. »Evangelischer Gottesdienst in Wien vor der Toleranzzeit.«Jahrbuch für die Geschichte des Protestantismus in Österreich 7: 120-31.

Patzelt, Herbert. 1999. Evangelisches Leben am Golf von Triest: Geschichte der evangelischen Gemeinde in Triest mit Abbazia, Görz, Fiume und Pola. München: Evang. Presseverband.

Reglement für die sämmentlich-Kaiserlich-Königliche Infanterie. 1769. Dunaj: Trattner. Reichsgesetzblattfürdas Kaiserthum Oesterreich.1861. Dunaj: Hof-und Staatsdruckerei.

Reichl-Ham, Claudia. 2005. Die Militärseelsorge in Geschichte und Gegenwart: Die evangelische Militärseelsorge von ihren Anfängen bis heute (Militär \& Seelsorge 4). Dunaj: Evang. Militärsuperintendentur.

Reiss, Wolfram. 2016. »Der Umgang mit religiösen Minderheiten in der österreichischen Armee.« Interdisciplinary Journal for Religion and Transformation in Contemporary Society 2 (1): 82-113.

Schima, Stefan. 2011/12. »Die Rechtsstellung der Evangelischen in Österreich zwischen der Erlassung des Toleranzpatents und der Revolution von 1848: Ein Vergleich mit der Rechtsstellung anderer Religionsgemeinschaften. "Jahrbuch für die Geschichte des Protestantismus in Österreich 127/128: 204-61.

Schmidl, Erwin A. 2014. Habsburgs jüdische Soldaten 1788-1918. Dunaj, Köln in Weimar: Böhlau.

Schwarz, Karl W. 1985. „Die Toleranz im Religionsrecht des Hlg. Römischen Reichs Deutscher Nation, in Brandenburg-Preußen und in Österreich." Österreichisches Archiv für Kirchenrecht 35: 258-81.

---. 1988. „Exercitium religionis privatum. Eine begriffsgeschichtliche Analyse.« Zeitschrift der Savigny-Stiftung für Rechtsgeschichte: Kanonistische Abteilung 74 (1): 495-518.

---. 2012a. »Das josefinische Toleranzpatent und seine Bedeutung für die evangelische Minderheit in Slowenien." V In Mandatis Meditari: Festschrift für Johann Paarhammer zum 65. Geburtstag (Kanonistische Studien und Texte 58), ur. Stephan Haering, Johann Hirnsperger, Gerlinde Katzinger inWilhelm Rees, 819-36. Berlin: Duncker \& Humblot.

---. 2012b. »ožefinski tolerančni patent in njegov pomen za evangeličansko manjšino v Sloveniji.« Stati inu obstati 8 (15-16): 17-34.

---. 2012c. »Das Ringen um Religionsfreiheit im Donau- und Karpatenraum zwischen 1681 und 1781." Historia Ecclesiastica 3 (1): 3-16.

---. 2016/17. »Der Anteil des Protestantismus an den Monarchie- und Kaiserjubiläen.» Jahrbuch für die Geschichte des Protestantismus in Österreich 132/133: 173-87. 
---. 2017. "Zur rechtsgeschichtlichen Einordnung des österreichischen Geheimprotestantismus." V Der österreichische Protestantismus im Spiegel seiner Rechtsgeschichte (Jus Ecclesiasticum 117), 1-24. Tübingen: Mohr Siebeck

Shek Brnardić, Teodora. 2010. »Modalities of Enlightened Monarchical Patriotism in the Mid-Eighteenth Century Habsburg Monarchy." V Whose Love of Which Country? Composite States, National Histories and Patriotic Discourses in Early Modern East Central Europe (Studies in the History of Political Thought 3), ur. Balazs Trencsenyi in Márton Zászkaliczky, 631-61. Leiden in Boston: Brill.

---. 2017. »The Upbringing of Competent and Patriotic Officers: Military Education at the Theresian .Military Academy in Wiener Neustadt (1752-1805).« Povijesni prilozi 36 (53): 109-32.

Silber, Michael K. 2005. »From Tolerated Aliens to Citizen-Soldiers: Jewish Military Service in the Era of Joseph II." V Constructing Nationalities in East Central Europe (Austrian and Habsburg Studies 6), ur. Pieter M. Judson in Marsha L. Rozenblit, 19-36. New York: Berghahn Books.

Statuten des löblichen militärischen Maria Theresien-Ordens. 1811. Dunaj: Hof- und Staats-Druckerey

Steiger, Andreas, in Manfred Gänsdorfer. 2002. „250 Jahre Theresianische Militärakademie - ein historischer Rückblick." Der Offizier 2, 12-17.

Stergar, Rok, in Tamara Scheer. 2018. »Ethnic Boxes: The Unintended Consequences of Habsburg Bureaucratic Classification.« Nationalities Papers 46 (4): 575-91.

Stökl, Erika. 1953. »Der Protestantismus in Wien von 1781-1848. «Jahrbuch für die Geschichte des Protestantismus in Österreich 68/69: 205-57.

Streffleur, Valentin von. 1848. Die Dienst-Vorschiften sämmtlicher Waffengattungen und Branchen der k.k. österreichischen Armee, 5. Abteilung: Die Vorschriften über die Personal-Angelegenheiten der k.k. österreichischen Militärs. Dunaj: Streffleur.

Tepperberg, Christoph. 1996. »Evangelische in Habsburgs Heer.« V Evangelische in Österreich: Vom Anteil der Protestanten an der österreichischen Kultur und Geschichte (Katalog zur gleichnamigen Ausstellung in der Österreichischen Nationalbibliothek, Wien, November 1996 bis Feber 1997), 130-36. Dunaj: Evang. Presseverband.

Tolerančni patent 1781. 2011. Prev. Jonatan Vinkler. Stati inu obstati 7 (13-14): 297-300.

Trauner, Karl-Reinhart. 2005. »Die Garnisonskirche in Wien: Ein vergessenes evangelisches Gotteshaus. "Jahrbuch für die Geschichte des Protestantismus in Österreich 121: 373-96.

---. 2011/12. „'Schicksalsergeben und fromm ...' Evangelische in Habsburgs Militär des 19. Jahrhunderts. "Jahrbuch für die Geschichte des Protestantismus in Österreich 127/128: 144-66. 
---. 2012. »Staatliche Ordnung als Gewaltregulativ.« V 'Krieg aller gegen alle' zum staatlichen Gewaltmonopol und zurück?, ur. Paul Georg Ertl in Jodok Troy, 3950. Frankfurt ob Majni, Berlin, Bern, Bruselj, New York, Oxford in Dunaj: Lang.

---. 2013. »'Mach er mir tüchtige Offiziers und rechtschaffene Männer daraus!' Anfänge einer konfessionellen Toleranz in Habsburgs Armee." Historia Ecclesiastica 4 (1): 137-51.

Trautenberger, Gustav. 1901. »Im Josefinischen Jahrzehnt (Schlußteil).» Jahrbuch für die Geschichte des Protestantismus in Österreich 22: 181-221.

Vinkler, Jonatan. 2011. »Ob Tolerančnem Patentu Jožefa II.« Stati inu obstati 7 (13-14): 301-6.

»Wurmser, Dagobert Siegmund Graf.«189o. Biographisches Lexikon des Kaiserthums Österreich [Wurzbach] 59, 1-7.

Iz nemščine prevedel Marko Kerševan 